\title{
On Modified Algorithm for Fourth-Grade Fluid
}

\author{
Farah Jabeen Awan, ${ }^{1}$ Asif Mehmood, ${ }^{2}$ Syed Tauseef Mohyud-Din, ${ }^{1}$ and Saleh M. Hassan ${ }^{3}$ \\ ${ }^{1}$ Department of Mathematics, Heavy Industries Taxila Education City University, Taxila Cantonment, Pakistan \\ ${ }^{2}$ Department of Mathematics, Air University, E-9, Islamabad 44000, Pakistan \\ ${ }^{3}$ Department of Mathematics, College of Science, King Saud University, P.O. Box 2455, Riyadh 11451, Saudi Arabia
}

Correspondence should be addressed to Syed Tauseef Mohyud-Din; tauseefsyedn@gmail.com

Received 17 July 2015; Revised 5 September 2015; Accepted 28 September 2015

Academic Editor: Mohsen Torabi

Copyright (C) 2015 Farah Jabeen Awan et al. This is an open access article distributed under the Creative Commons Attribution License, which permits unrestricted use, distribution, and reproduction in any medium, provided the original work is properly cited.

This paper shows the analysis of the thin film flow of fourth-grade fluid on the outer side of a vertical cylinder. Solution of the governing nonlinear equation is obtained by Rational Homotopy Perturbation Method (RHPM); comparison with exact solution reflects the reliability of the method. Analysis shows that this method is reliable for even high nonlinearity. Graphs and tables strengthen the idea.

\section{Introduction}

Recently, a number of new and modified techniques have been introduced by various scientists which subsequently proved extremely useful to tackle various nonlinear problems of diversified physical nature. It is an established fact that most of the physical problems in nature are nonlinear and hence solutions of such problems are of utmost importance. In a similar context, Rational Homotopy Perturbation Method (RHPM) [1] is a newly developed modified form of Homotopy Perturbation Method (HPM). HPM is developed by the coupling of Homotopy and perturbation is very useful for solving nonlinear problems [2-16]. The literature reveals that Jalaal et al. applied Homotopy Perturbation Method to find the velocity profile of a spherical solid particle in plane Couette fluid flow [2]. Liao compared Homotopy Analysis and Homotopy Perturbation Method [3], and Ghorbani and Nadjafi made an elegant comparison of He's polynomials which are obtained from Homotopy Perturbation Method (HPM) Adomian's Polynomials [4]. They worked on new developments of the HPM [5]. Mohyud-Din applied HPM on various problems like partial differential equations, higher dimensional initial boundary value problem, and fourthorder, nonlinear higher-order, and sixth-order boundary value problems [6-10]. Xu solved boundary layer equation in unbounded domain by HPM [11]. Vázquez-Leal [1] modified the idea of Homotopy Perturbation Method. He used two power series of Homotopy parameters in a quotient, resulting in a series of linear differential equations.

Siddiqui applied Homotopy Perturbation Method on thin film flow of fourth-grade fluid on the outer wall of vertical cylinder. Hayat applied Homotopy Analysis Method on the same problem and proved convergence. Afterwards, Sajid introduced the slip effect for this problem and presented solution using Homotopy Analysis Method [12-16].

It is worth mentioning that Hayat et al. $[17,18]$ made an appropriate use of Homotopy technique and applied the same on thin film flow of an Oldroyd 6-constant fluid over a moving belt [17] and also on Couette and Poiseuille flows for fourth-grade fluid [18]. It is to be highlighted that the proposed method (RHPM) is highly suitable for a wide range of physical problems including heat transfer and thermodynamics. The detailed study of the literature reconfirms the reliability of the suggested Rational Homotopy Perturbation Method (see [19-23] and the references therein). In a similar context, Ganji et al. [20, 21] solved nonlinear equations arising in heat transfer by applying the coupling of Homotopy and perturbation. Moreover, Chowdhury and Hashim [22] and Islam et al. [23] extended modified version of Homotopy Perturbation Method for problems related to 
heat transfer. Inspired and motivated by the ongoing research in this area, we apply a relatively new modified version of Homotopy Perturbation Method which is called Rational Homotopy Perturbation Method (RHPM) [24] on the thin film flow of fourth-grade fluid coupled with slip effect. A convergent and reliable solution is presented with the aid of figures and tables. Analysis shows that Rational Homotopy Perturbation Method is adequate to present the flow behavior of this problem. It is observed that RHPM is very efficient for such problems. Moreover, RHPM is equally applicable on the mathematical models derived from nature like Stiff system of equations [24], transient of nonlinear circuits [19], and heat transfer problems (see [19-24] and the references therein).

\section{Basic Idea of RHPM}

Foundation of Rational Homotopy Perturbation Method and Homotopy Perturbation Method is the same. Consider the nonlinear differential equation to explain both methods:

$$
L(u)+N(u)-g(r)=0, \quad \text { where } r \in \Omega,
$$

and consider the boundary condition

$$
B\left(u, \frac{\partial u}{\partial \eta}\right), \quad \text { where } r \in \Gamma,
$$

where $N$ and $L$ are nonlinear and linear operators, respectively, and $B$ is a boundary operator. $g(r)$ is an analytic function and domain $\Omega$ has the boundary $\Gamma$. Homotopy can be written as

$$
\begin{aligned}
H(v, p)= & (1-p)\left[L(v)-L\left(u_{0}\right)\right] \\
& +p(L(v)+N(v)-g(r))=0,
\end{aligned}
$$

$$
p \in[0,1]
$$

where $u_{0}$ is an initial approximation for (1) which satisfies the boundary condition and Homotopy parameter is $p$. For $p=0$ and $p=1$, (3) can be written as

$$
\begin{aligned}
& H(v, 0)=\left[L(v)-L\left(u_{0}\right)\right]=0, \\
& H(v, 1)=L(v)+N(v)-g(r)=0 .
\end{aligned}
$$

For HPM, let us take the solution for (3) as

$$
v=v_{0}+p v_{1}+p^{2} v_{2}+\cdots
$$

consider $p \rightarrow 1$ to get approximate solution

$$
u(y)=\lim _{p \rightarrow 1} v=v_{0}+v_{1}+v_{2}+\cdots .
$$

Let us take the solution of (3) for RHPM as

$$
v=\frac{v_{0}+p v_{1}+p^{2} v_{2}+\cdots}{\psi_{0}+p \psi_{1}+p^{2} \psi_{2} \cdots},
$$

where known analytic functions $\psi_{0}, \psi_{1}, \psi_{2} \ldots$ have independent variables and unknown functions $v_{0}, v_{1}, v_{2} \ldots$ are to be determined by the Rational Homotopy Perturbation Method. An approximate solution of (1) is obtained when limiting case of (7) is taken as $p \rightarrow 1$. Hence,

$$
u=\frac{v_{0}+v_{1}+v_{2}+\cdots}{\psi_{0}+\psi_{1}+\psi_{2} \cdots} .
$$

The limiting case in the above equation is associated with existence of limits

$$
\begin{gathered}
\lim _{p \rightarrow 1}\left(\sum_{i=0}^{\infty} v_{i}\right), \\
\lim _{p \rightarrow 1}\left(\sum_{i=0}^{\infty} \psi_{i}\right), \quad \text { where } \sum_{i=0}^{\infty} \psi_{i} \neq 0 .
\end{gathered}
$$

\section{Solution by RHPM}

Let us consider the dimensionless equation representing thin film flow of fourth-grade fluid which is falling on the outer side of a vertical cylinder having an infinite length of radius $R[13]$ :

$$
\begin{aligned}
& x \frac{d^{2} u}{d x^{2}}+\frac{d u}{d x}+K x+2 \beta\left[\left(\frac{d u}{d x}\right)^{3}+3\left(\frac{d u}{d x}\right)^{2} \frac{d^{2} u}{d x^{2}}\right] \\
& =0
\end{aligned}
$$

where $\beta$ is nondimensional fluid parameter, $K$ is dimensionless constant which corresponds to gravity, and $M$ corresponds to partial slip effect. Boundary condition is

$$
\begin{aligned}
u(x)-\frac{M K}{2}\left(l^{2}-1\right)=0 & \text { at } x=1, \\
\frac{d u(x)}{d x}=0 & \text { at } x=l .
\end{aligned}
$$

Exact solution is

$$
u(x)=\int_{1}^{x} g(\widehat{x}) d \widehat{x}+\frac{M K}{2}\left(l^{2}-1\right), \quad 1 \leq x \leq l,
$$

where 


$$
g(x)=\frac{2^{5 / 3} 3^{1 / 3} \beta x^{2}+\left[-\left(18 \beta^{2} K x^{2}\left(x^{2}-l^{2}\right)\right)+\sqrt{3\left\{32 \beta^{3} x^{6}+108 \beta^{4} K^{2} x^{4}\left(x^{2}-l^{2}\right)^{2}\right\}}\right]^{2 / 3}}{2^{4 / 3} 3^{2 / 3} \beta x\left[-\left(18 \beta^{2} K x^{2}\left(x^{2}-l^{2}\right)\right)+\sqrt{3\left\{32 \beta^{3} x^{6}+108 \beta^{4} K^{2} x^{4}\left(x^{2}-l^{2}\right)^{2}\right\}}\right]^{1 / 3}} .
$$

Integral in (12) can be calculated numerically.

Consider the following Homotopy equation:

$$
\begin{aligned}
& (1-p)\left(x v^{\prime \prime}+v^{\prime}-\left(u_{0}^{\prime}+x u_{0}^{\prime \prime}\right)\right) \\
& +p\left(x v^{\prime \prime}+v^{\prime}+k x+2 \beta\left(v^{\prime}\right)^{3}+3\left(v^{\prime}\right)^{2} v^{\prime \prime}\right),
\end{aligned}
$$

where $u_{0}=(M K / 2)\left(l^{2}-1\right)+(K / 4)\left(1-x^{2}+2 l^{2} \log [x]\right)$ is initial approximation. Let us consider the solution of $(14)$ with $[2,2]$ order of approximation as

$$
v=\frac{v_{0}(x)+p v_{1}(x)+p^{2} v_{2}(x)}{1+a p x^{2}+b p^{2} x^{4}}
$$

where $a$ and $b$ are the adjustment parameters. By considering (14) and (15) and regrouping according to the $p$-powers, we get the following.

Zeroth-Order Problem. The zeroth-order problem is as follows:

$$
-\frac{k l^{2}}{x}+k x+v_{0}^{\prime}+x v_{0}^{\prime \prime}=0,
$$

subject to the boundary conditions

$$
\begin{array}{cl}
v_{0}(x)=1 & \text { at } x=0, \\
\frac{d v_{0}(x)}{d x}=0 & \text { at } x=1 .
\end{array}
$$

First-Order Problem. The first-order problem is as follows:

$$
\begin{gathered}
-\frac{k l^{2}}{x}-4 a x v_{0}-4 a x^{2} v_{0}^{\prime}+2 \beta\left(v_{0}^{\prime}\right)^{3}+v_{1}^{\prime} \\
+6 x \beta\left(v_{0}^{\prime}\right)^{2} v_{0}^{\prime \prime}+x v_{1}^{\prime \prime}=0,
\end{gathered}
$$

and relevant boundary conditions are

$$
\begin{array}{cc}
v_{1}(x)=0 & \text { at } x=0, \\
\frac{d v_{1}(x)}{d x}=0 & \text { at } x=1 .
\end{array}
$$

Second-Order Problem. The second-order problem is as follows:

$$
\begin{aligned}
& 8 a^{2} x^{3} v_{0}-16 b x^{3} v_{0}-4 a x v_{1}-8 b x^{4} v_{0}^{\prime}-24 a x \beta v_{0} v_{0}^{\prime 2} \\
& -24 a x^{2} \beta v_{0}^{\prime 3}-4 a x^{2} v_{1}^{\prime}+6 \beta\left(v_{0}^{\prime}\right)^{2} v_{1}^{\prime}+v_{2}^{\prime} \\
& -24 a x^{2} \beta v_{0} v_{0}^{\prime} v_{0}^{\prime \prime}+12 x \beta v_{0}^{\prime} v_{1}^{\prime} v_{0}^{\prime \prime}+6 x \beta\left(v_{0}^{\prime}\right)^{2} v_{1}^{\prime \prime} \\
& +x v_{2}^{\prime \prime}=0
\end{aligned}
$$

and relevant boundary conditions are

$$
\begin{array}{rr}
v_{2}(x)=0 & \text { at } x=0, \\
\frac{d v_{2}(x)}{d x}=0 & \text { at } x=1 .
\end{array}
$$

Solving these problems with the corresponding boundary conditions, we have

$$
\begin{aligned}
v_{0} & =\frac{1}{4}\left(K-2 K M+2 K l^{2} M-K x^{2}+2 K l^{2} \log [x]\right. \\
& \left.-4 K l^{2} \log [l] \log [x]+2 K l^{2} \log [x]^{2}\right), \\
v_{1} & =\frac{1}{16 x^{2}}\left(-a K x^{2}+4 a K l^{2} x^{2}+8 a K M x^{2}\right. \\
& -8 a K l^{2} M x^{2}+4 a K x^{2}-4 a K l^{2} x^{4}-8 a K M x^{4} \\
& +8 a K l^{2} M x^{4}-3 a K x^{6}+32 K^{3} l^{6} \beta-K^{3} x^{2} \beta \\
& -32 K^{3} l^{6} x^{2} \beta+K^{3} x^{6} \beta-60 K^{3} l^{6} \beta \log [l] \\
& \left.-12 K^{3} l^{2} x^{2} \beta \log [l]+60 K^{3} l^{6} x^{2} \beta \log [l]+\cdots\right), \\
v_{2} & =\frac{1}{5760 x^{4}}\left(280 a^{2} K x^{4}-160 \beta 1 K x^{4}-1440 a l^{2} x^{4}\right. \\
& -270 a^{2} K 0 l^{2} x^{4}+360 \beta K l^{2} x^{4}-2160 a^{2} K M x^{4} \\
& +2880 \beta K M x^{4}+2160 a^{2} K l^{2} M x^{4} \\
& \left.-2880 \beta K l^{2} M x^{4}-360 a^{2} K x^{6} \cdots\right) .
\end{aligned}
$$

Substituting (22) into (15) and assuming $p \rightarrow 1$ result in

$$
\begin{aligned}
u(x) & =\left(\frac { 1 } { 4 } \left(K-2 K M+2 K l^{2} M-K x^{2}\right.\right. \\
& +2 K l^{2} \log [x]-4 K l^{2} \log [l] \log [x] \\
& \left.+2 K l^{2} \log [x]^{2}\right)+\frac{1}{16 x^{2}}\left(-a K x^{2}+4 a K l^{2} x^{2}\right. \\
& +8 a K M x^{2}-8 a K l^{2} M x^{2}+4 a K x^{2}-4 a K l^{2} x^{4} \\
& -8 a K M x^{4}+8 a K l^{2} M x^{4}-3 a K x^{6}+32 K^{3} l^{6} \beta \\
& -K^{3} x^{2} \beta-32 K^{3} l^{6} x^{2} \beta+K^{3} x^{6} \beta-60 K^{3} l^{6} \beta \log [l] \\
& \left.-12 K^{3} l^{2} x^{2} \beta \log [l]+60 K^{3} l^{6} x^{2} \beta \log [l]+\cdots\right) \\
& +\frac{1}{5760 x^{4}}\left(280 a^{2} K x^{4}-160 \beta 1 K x^{4}-1440 a l^{2} x^{4}\right.
\end{aligned}
$$




$$
\begin{aligned}
& -270 a^{2} K 0 l^{2} x^{4}+360 \beta K l^{2} x^{4}-2160 a^{2} K M x^{4} \\
& +2880 \beta K M x^{4}+2160 a^{2} K l^{2} M x^{4} \\
& \left.\left.-2880 \beta K l^{2} M x^{4}-360 a^{2} K x^{6} \cdots\right)+\cdots\right)\left(1+a x^{2}\right. \\
& \left.+b x^{4}\right)^{-1}
\end{aligned}
$$

Now, let us discuss the solution for different parameters.

Case $1(k=1, M=0.1, \beta=0.1$, and $l=1.5)$. Choosing the adjustment parameters for (23) as $a=0.00487593$ and $b=-0.0013628$, we have

$$
\begin{aligned}
& u(x)=\left(\frac { 1 } { 4 } \left(K-2 K M+2 K l^{2} M-K x^{2}\right.\right. \\
& +2 K l^{2} \log [x]-4 K l^{2} \log [l] \log [x] \\
& \left.+2 K l^{2} \log [x]^{2}\right)+\frac{1}{16 x^{2}}\left(-a K x^{2}+4 a K l^{2} x^{2}\right. \\
& +8 a K M x^{2}-8 a K l^{2} M x^{2}+4 a K x^{2}-4 a K l^{2} x^{4} \\
& -8 a K M x^{4}+8 a K l^{2} M x^{4}-3 a K x^{6}+32 K^{3} l^{6} \beta \\
& \left.-K^{3} x^{2} \beta-32 K^{3} l^{6} x^{2} \beta+K^{3} x^{6} \beta-60 K^{3} l^{6} \beta \log ^{2} l\right] \\
& \left.\left.-12 K^{3} l^{2} x^{2} \beta \log ^{2} l\right]+60 K^{3} l^{6} x^{2} \beta \log [l]+\cdots\right) \\
& +\frac{1}{5760 x^{4}}\left(280 a^{2} K x^{4}-160 \beta 1 K x^{4}-1440 a l^{2} x^{4}\right. \\
& -270 a^{2} K 0 l^{2} x^{4}+360 \beta K l^{2} x^{4}-2160 a^{2} K M x^{4} \\
& +2880 \beta K M x^{4}+2160 a^{2} K l^{2} M x^{4} \\
& +
\end{aligned}
$$

Case $2(k=1, M=0.3, \beta=0.5$, and $l=1.5])$. Choosing the adjustment parameters for (23) as $a=-0.0011041205$ and $b=0.001978206018$, we have

$$
\begin{aligned}
u(x) & =\left(\frac { 1 } { 4 } \left(K-2 K M+2 K l^{2} M-K x^{2}\right.\right. \\
& +2 K l^{2} \log [x]-4 K l^{2} \log [l] \log [x] \\
& \left.+2 K l^{2} \log [x]^{2}\right)+\frac{1}{16 x^{2}}\left(-a K x^{2}+4 a K l^{2} x^{2}\right. \\
& +8 a K M x^{2}-8 a K l^{2} M x^{2}+4 a K x^{2}-4 a K l^{2} x^{4} \\
& -8 a K M x^{4}+8 a K l^{2} M x^{4}-3 a K x^{6}+32 K^{3} l^{6} \beta \\
& -K^{3} x^{2} \beta-32 K^{3} l^{6} x^{2} \beta+K^{3} x^{6} \beta-60 K^{3} l^{6} \beta \log [l] \\
& \left.-12 K^{3} l^{2} x^{2} \beta \log [l]+60 K^{3} l^{6} x^{2} \beta \log [l]+\cdots\right)
\end{aligned}
$$

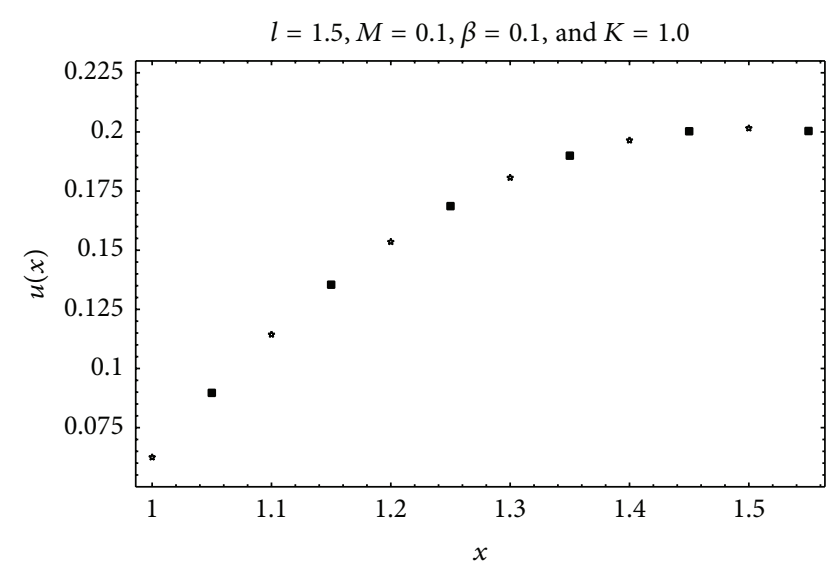

* RHPM

- Exact

FIGURE 1: Comparison of RHPM with exact solution.

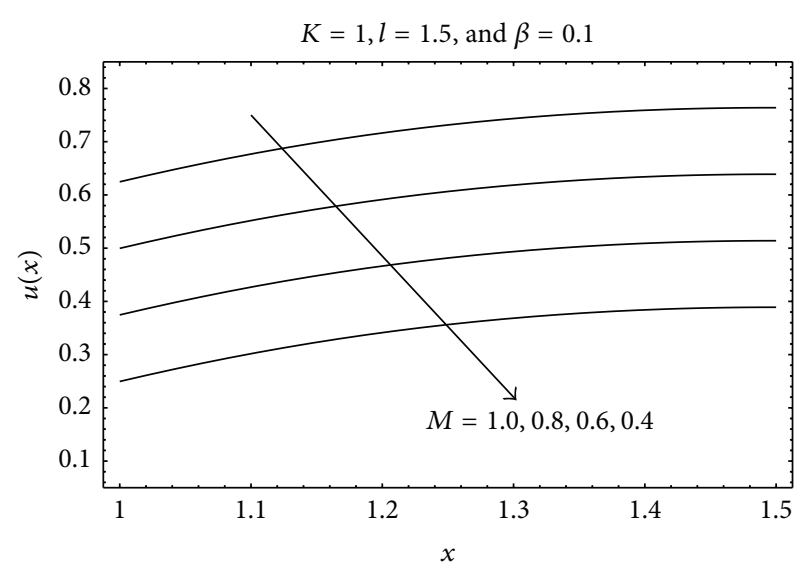

FIGURE 2: Effect of $M$ on velocity profile.

$$
\begin{aligned}
& +\frac{1}{5760 x^{4}}\left(280 a^{2} K x^{4}-160 \beta 1 K x^{4}-1440 a l^{2} x^{4}\right. \\
& -270 a^{2} K 0 l^{2} x^{4}+360 \beta K l^{2} x^{4}-2160 a^{2} K M x^{4} \\
& +2880 \beta K M x^{4}+2160 a^{2} K l^{2} M x^{4} \\
& \left.\left.-2880 \beta K l^{2} M x^{4}-360 a^{2} K x^{6} \cdots\right)+\cdots\right)(1 \\
& \left.-0.0011041205 x^{2}+0.0019782060 x^{4}\right)^{-1}
\end{aligned}
$$

\section{Conclusion}

In this section, we will give analysis of the present attempt. Figure 1 shows that solution found by Rational Homotopy Perturbation Method overlaps with exact solution. Figure 2 represents the notion that there exists a gradual shift of velocity with varying slip effect. By increasing the slip effect, 


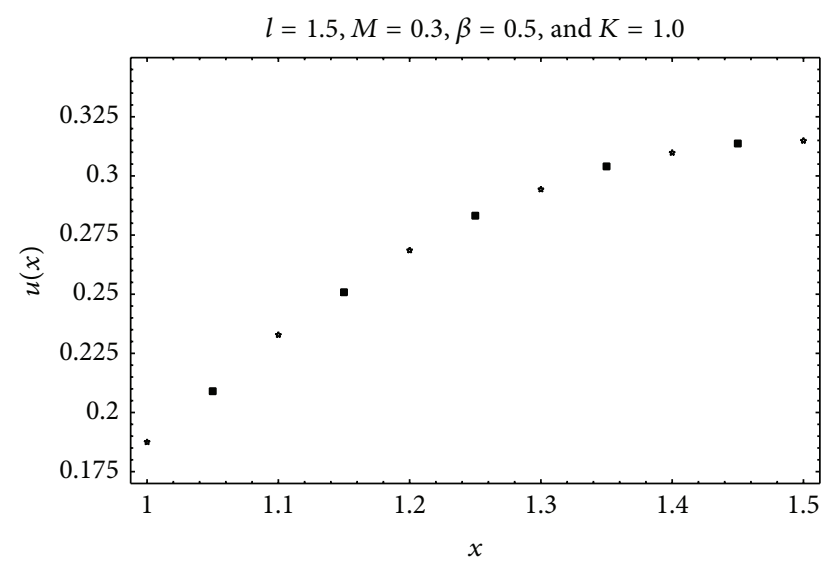

- RHPM

- Exact

FIgURE 3: Comparison of RHPM with exact solution.

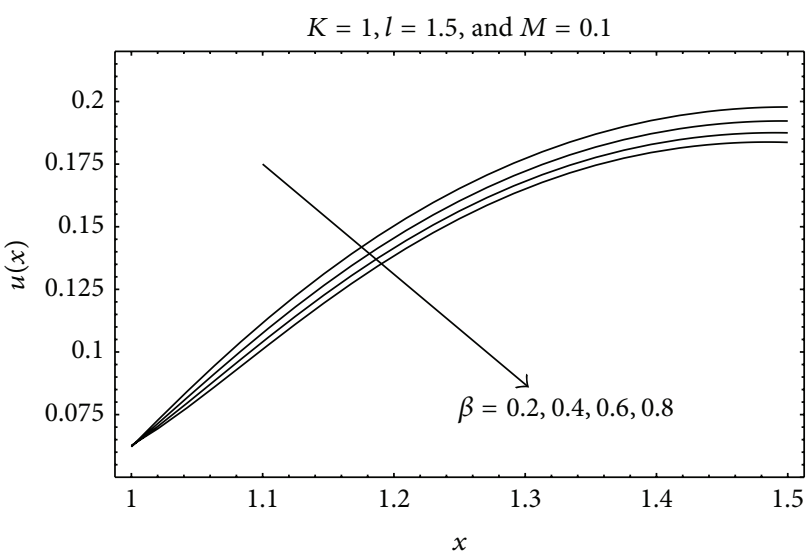

FIgURE 4: Effect of $\beta$ on velocity profile.

velocity also increases. Figure 3 shows that, by increasing the nonlinearity and slip effect, Rational Homotopy Perturbation Method and exact solutions are in good agreement. Figure 4 represents the effect of $\beta$ on the velocity. Tables 1-2 show that error is negligible. Table 3 shows that, for different values of slip effects, Rational Homotopy Perturbation Method efficiently represents the flow behavior. Table 4 reflects the reliability of the method for different values of $\beta$. Tables 34 demand that $a$ and $b$ be determined individually by the method described in Cases 1 and 2. Mathematica 5.2 is used in all calculations.

\section{Conflict of Interests}

The authors declare that there is no conflict of interests regarding the publication of this paper.
TABLE 1: Flow behavior and error estimation of fluid for $K=1, M=$ $0.1, \beta=0.1$, and $l=1.5$.

\begin{tabular}{lcc}
\hline$x$ & RHPM & Numerical RHPM \\
\hline 1.0 & 0.0622812 & $2.18802 E-4$ \\
1.1 & 0.114139 & $2.46544 E-4$ \\
1.2 & 0.153569 & $-2.6404 E-5$ \\
1.3 & 0.180729 & $-5.56143 E-5$ \\
1.4 & 0.196448 & $8.225052 E-6$ \\
1.5 & 0.201573 & $-4.88900 E-6$ \\
\hline
\end{tabular}

TABLE 2: Flow behavior and error estimation for $K=1, M=0.3$, $\beta=0.5$, and $l=1.5$.

\begin{tabular}{lcc}
\hline$x$ & RHPM & Numerical RHPM \\
\hline 1.0 & 0.187336 & $1.63748 E-4$ \\
1.1 & 0.230755 & $2.06236 E-3$ \\
1.2 & 0.268424 & $1.31266 E-4$ \\
1.3 & 0.295047 & $-7.2133 E-4$ \\
1.0 & 0.310211 & $-4.2611 E-4$ \\
1.5 & 0.314603 & $2.72582 E-4$ \\
\hline
\end{tabular}

TABLE 3: Error table for $k=1, \beta=0.1$, and $l=1.5$

\begin{tabular}{cccc}
\hline & $M=0.4$ & $M=0.8$ & $M=1.0$ \\
$x$ & $a=0.0016161$ & $a=0.000470222$ & $a=0.0002958$ \\
& $b=0.0000202$ & $b=0.000244044$ & $b=0.0002376$ \\
\hline 1.0 & $4.08412 E-4$ & $3.56878 E-4$ & $3.33297 E-4$ \\
1.1 & $1.35926 E-4$ & $6.35029 E-5$ & $4.41049 E-5$ \\
1.2 & $-2.85247 E-4$ & $-3.51118 E-4$ & $-3.65604 E-4$ \\
1.3 & $-3.1902 E-4$ & $-3.49445 E-4$ & $-3.57517 E-4$ \\
1.4 & $-1.30714 E-4$ & $-9.74395 E-5$ & $-9.70654 E-5$ \\
1.5 & $8.70222 E-5$ & $2.09943 E-4$ & $2.21282 E-4$ \\
\hline
\end{tabular}

TABLE 4: Error table for $k=1, M=0.1$, and $l=1.5$.

\begin{tabular}{cccc}
\hline & $\beta=0.2$ & $\beta=0.6$ & $\beta=0.8$ \\
$x$ & $a=0.006301675$ & $a=-0.002555156$ & $a=-0.01257134$ \\
& $b=-0.00121253$ & $b=0.0042851561$ & $b=0.009340074$ \\
\hline 1.0 & $3.1646 E-4$ & $1.07938 E-4$ & $2.02609 E-4$ \\
1.1 & $6.06636 E-4$ & $2.68093 E-3$ & $3.84367 E-3$ \\
1.2 & $-3.04017 E-5$ & $3.02243 E-4$ & $5.24388 E-4$ \\
1.3 & $-1.72439 E-4$ & $-8.45452 E-4$ & $-1.24596 E-3$ \\
1.4 & $-1.32375 E-5$ & $-5.49597 E-4$ & $-8.79013 E-4$ \\
1.5 & $1.11499 E-4$ & $3.11275 E-4$ & $5.13033 E-4$ \\
\hline
\end{tabular}

\section{Acknowledgment}

This project was funded by the National Plan for Science, Technology and Innovation (MAARIFA), King Abdulaziz City for Science and Technology, Kingdom of Saudi Arabia, Award no. 15-MAT4688-02. 


\section{References}

[1] H. Vázquez-Leal, "Rational homotopy perturbation method," Journal of Applied Mathematics, vol. 2012, Article ID 490342, 14 pages, 2012.

[2] M. Jalaal, M. G. Nejad, P. Jalili et al., "Homotopy perturbation method for motion of a spherical solid particle in plane couette fluid flow," Computers \& Mathematics with Applications, vol. 61, no. 8, pp. 2267-2270, 2011.

[3] S. J. Liao, "Comparison between the homotopy analysis method and homotopy perturbation method," Applied Mathematics and Computation, vol. 169, no. 2, pp. 1186-1194, 2005.

[4] A. Ghorbani and J. S. Nadjafi, "He's homotopy perturbation method for calculating adomian polynomials," International Journal of Nonlinear Sciences and Numerical Simulation, vol. 8, no. 2, pp. 229-232, 2007.

[5] J.-H. He, "Recent developments of the homotopy perturbation method recent developments of the homotopy perturbation method," Topological Methods in Nonlinear Analysis, vol. 31, no. 2, pp. 205-209, 2008.

[6] S. T. Mohyud-Din and M. A. Noor, "Homotopy perturbation method for solving fourth-order boundary value problems," Mathematical Problems in Engineering, vol. 2007, Article ID 98602, 15 pages, 2007.

[7] S. T. Mohyud-Din and M. A. Noor, "Homotopy perturbation method for solving partial differential equations," Zeitschrift für Naturforschung A, vol. 64, no. 3-4, pp. 157-170, 2009.

[8] M. A. Noor and S. T. Mohyud-Din, "Homotopy perturbation method for solving nonlinear higher-order boundary value problems," International Journal of Nonlinear Sciences and Numerical Simulation, vol. 9, no. 4, pp. 395-408, 2008.

[9] M. A. Noor and S. T. Mohyud-Din, "Homotopy perturbation method for solving sixth-order boundary value problems," Computers and Mathematics with Applications, vol. 55, no. 12, pp. 2953-2972, 2008.

[10] M. A. Noor and S. T. Mohyud-Din, "Variational homotopy perturbation method for solving higher dimensional initial boundary value problems," Mathematical Problems in Engineering, vol. 2008, Article ID 696734, 11 pages, 2008.

[11] L. Xu, "He's homotopy perturbation method for a boundary layer equation in unbounded domain," Computers \& Mathematics with Applications, vol. 54, no. 7-8, pp. 1067-1070, 2007.

[12] M. Sajid and T. Hayat, "The application of homotopy analysis method to thin film flows of a third order fluid," Chaos, Solitons \& Fractals, vol. 38, no. 2, pp. 506-515, 2008.

[13] M. Sajid, M. Awais, S. Nadeem, and T. Hayat, "The influence of slip condition on thin film flow of a fourth grade fluid by the homotopy analysis method," Computers and Mathematics with Applications, vol. 56, no. 8, pp. 2019-2026, 2008.

[14] R. Ellahi and M. Hameed, "Numerical analysis of steady nonnewtonian flows with heat transfer analysis, MHD and nonlinear slip effects," International Journal of Numerical Methods for Heat and Fluid Flow, vol. 22, no. 1, pp. 24-38, 2012.

[15] M. Sheikholeslami, R. Ellahi, M. Hassan, and S. Soleimani, "A study of natural convection heat transfer in a nanofluid filled enclosure with elliptic inner cylinder," International Journal of Numerical Methods for Heat \& Fluid Flow, vol. 24, no. 8, pp. 1906-1927, 2014.

[16] M. Nawaz, A. Zeeshan, R. Ellahi, S. Abbasbandy, and S. Rashidi, "Joules and Newtonian heating effects on stagnation point flow over a stretching surface by means of genetic algorithm and Nelder-Mead method," International Journal of Numerical Methods for Heat \& Fluid Flow, vol. 25, no. 3, pp. 665-684, 2015.

[17] T. Hayat, R. Ellahi, and F. M. Mahomed, "Exact solution of a thin film flow of an Oldroyd 6-constant fluid over a moving belt," Communications in Nonlinear Science and Numerical Simulation, vol. 14, no. 1, pp. 133-139, 2009.

[18] T. Hayat, R. Ellahi, and F. M. Mahomed, "Exact solutions for Couette and Poiseuille flows for fourth grade fluids," Acta Mechanica, vol. 188, no. 1-2, pp. 69-78, 2007.

[19] H. Vazquez-Leal, K. Boubaker, L. Hernandez-Martinez, and J. Huerta-Chua, "Approximation for transient of nonlinear circuits using RHPM and BPES methods," Journal of Electrical and Computer Engineering, vol. 2013, Article ID 973813, 6 pages, 2013.

[20] D. D. Ganji, “The application of He's homotopy perturbation method to nonlinear equations arising in heat transfer," Physics Letters, Section A: General, Atomic and Solid State Physics, vol. 355, no. 4-5, pp. 337-341, 2006.

[21] D. D. Ganji and A. Sadighi, "Application of homotopyperturbation and variational iteration methods to nonlinear heat transfer and porous media equations," Journal of Computational and Applied Mathematics, vol. 207, no. 1, pp. 24-34, 2007.

[22] M. S. H. Chowdhury and I. Hashim, "Analytical solutions to heat transfer equations by homotopy-perturbation method revisited," Physics Letters A: General, Atomic and Solid State Physics, vol. 372, no. 8, pp. 1240-1243, 2008.

[23] S. Islam, R. A. Shah, I. Ali, and N. M. Allah, "Optimal homotopy asymptotic solutions of couette and poiseuille flows of a third grade fluid with heat transfer analysis," International Journal of Nonlinear Sciences and Numerical Simulation, vol. 11, no. 6, pp. 389-400, 2011.

[24] J. Biazar, M. A. Asadi, and F. Salehi, "Rational Homotopy Perturbation Method for solving stiff systems of ordinary differential equations," Applied Mathematical Modelling, vol. 39, no. 3-4, pp. 1291-1299, 2015. 


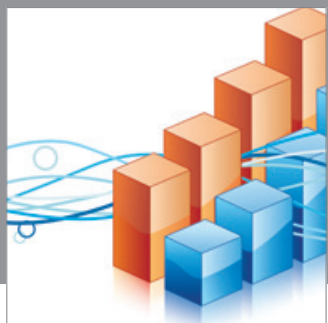

Advances in

Operations Research

mansans

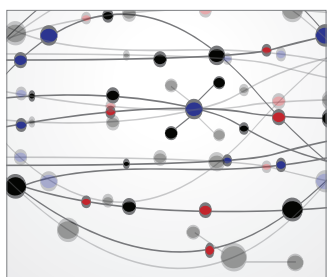

The Scientific World Journal
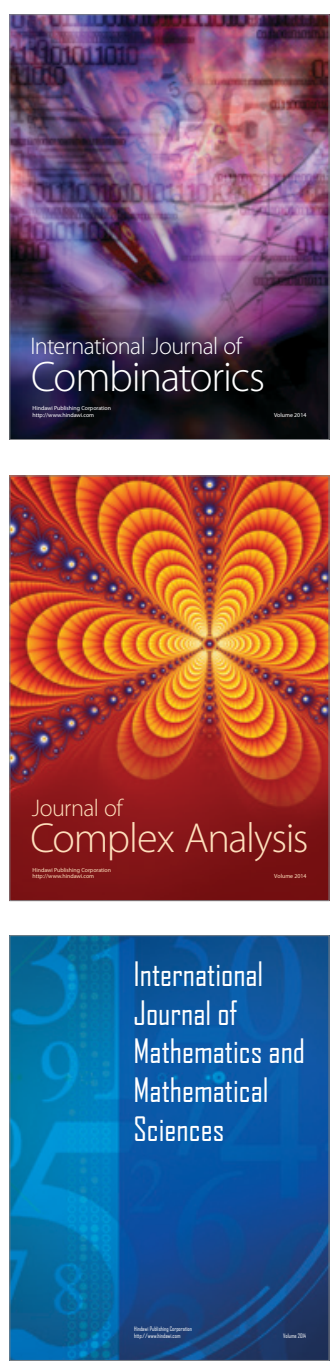
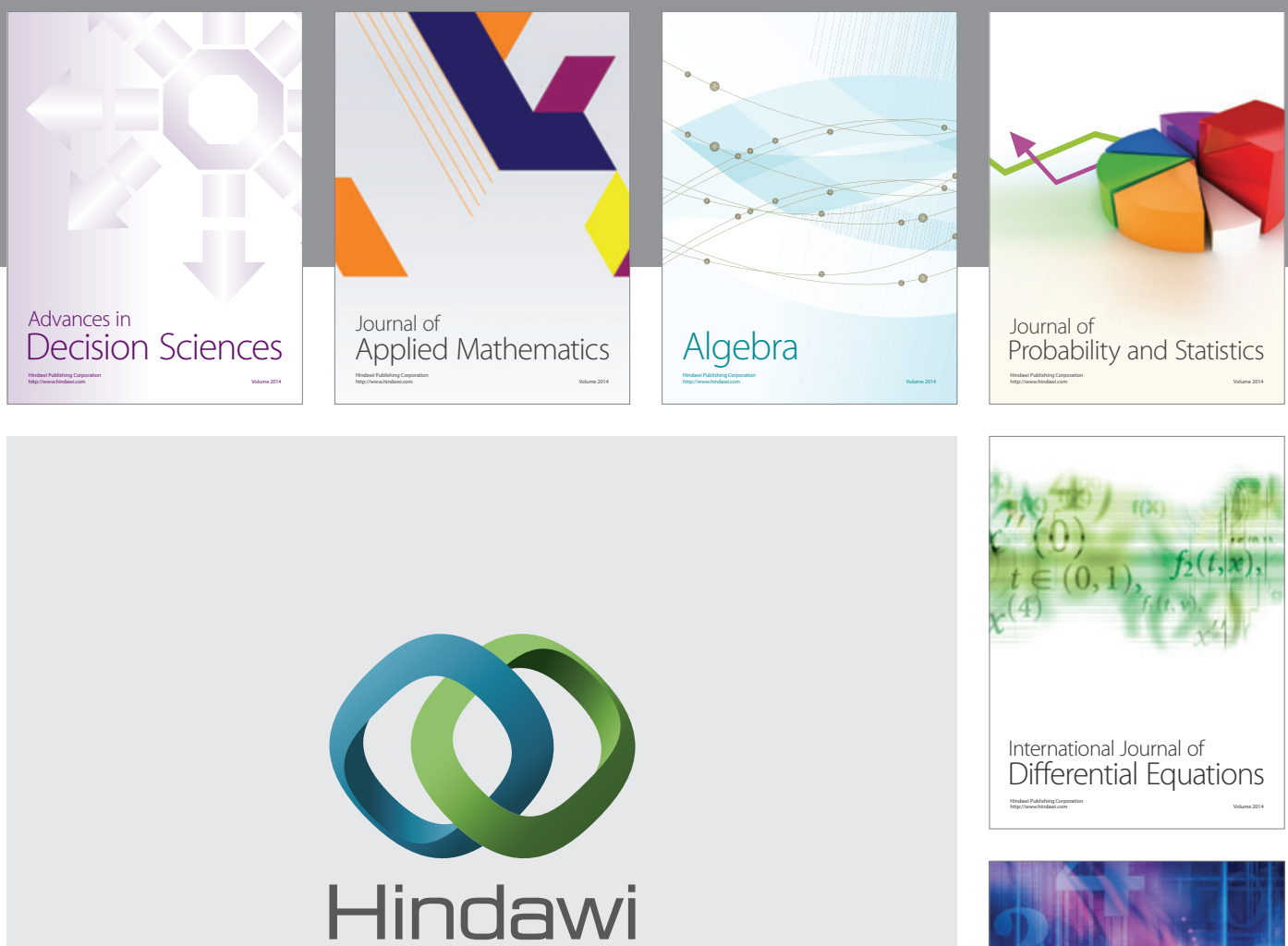

Submit your manuscripts at http://www.hindawi.com
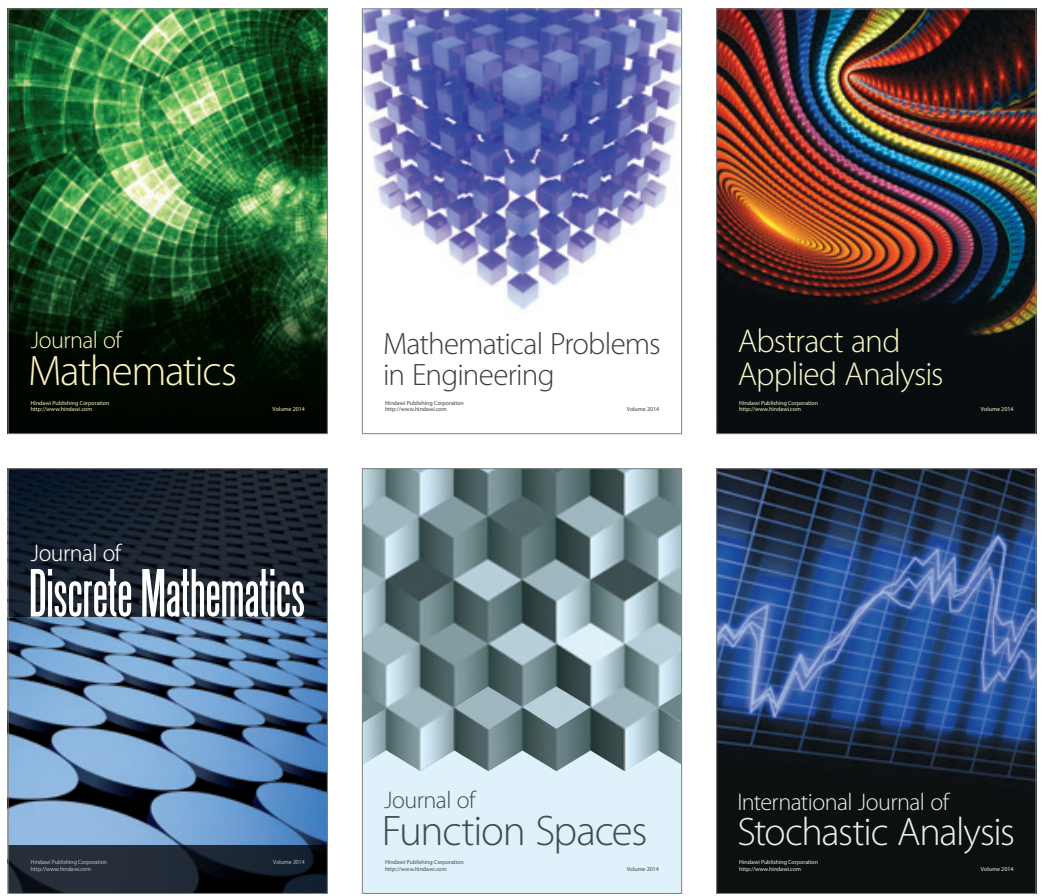

Journal of

Function Spaces

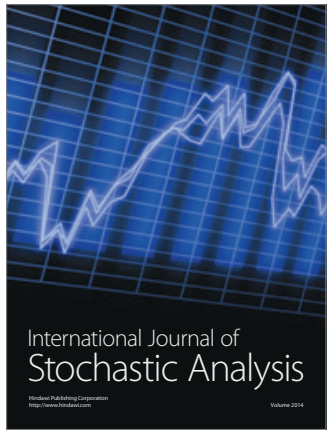

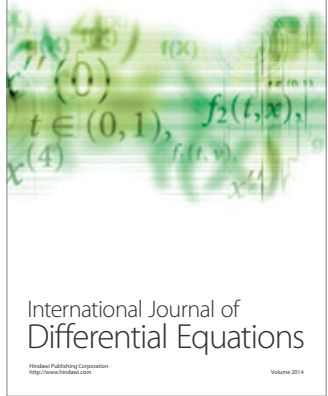
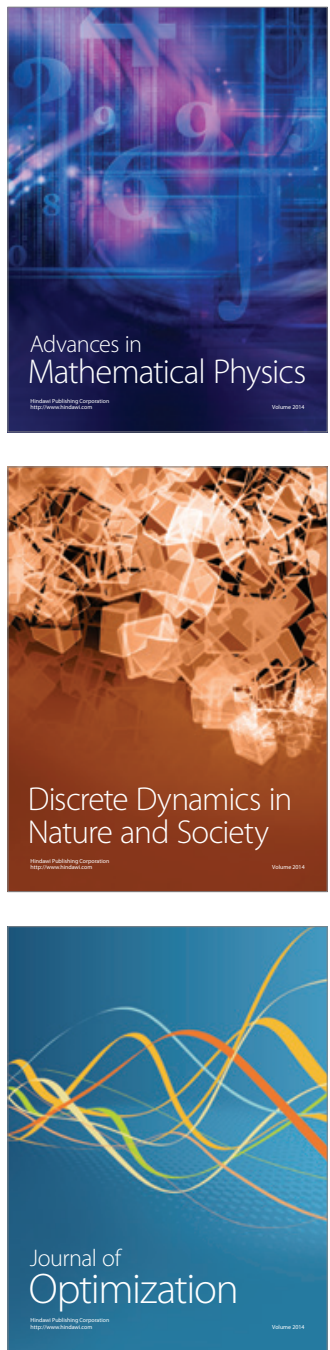